\title{
Lifestyle, Diet, and Colorectal Cancer Risk According to (Epi)genetic Instability: Current Evidence and Future Directions of Molecular Pathological Epidemiology
}

\author{
Laura A. E. Hughes ${ }^{1} \cdot$ Colinda C. J. M. Simons $^{1}$ • Piet A. van den Brandt ${ }^{1}$ • \\ Manon van Engeland ${ }^{2} \cdot$ Matty P. Weijenberg $^{1}$
}

Published online: 2 December 2017

(C) The Author(s) 2017. This article is an open access publication

\begin{abstract}
Purpose of Review In this review, we describe molecular pathological epidemiology (MPE) studies from around the world that have studied diet and/or lifestyle factors in relation to molecular markers of (epi)genetic pathways in colorectal cancer (CRC), and explore future perspectives in this realm of research. The main focus of this review is diet and lifestyle factors for which there is evidence for an association with CRC as identified by the World Cancer Research Fund reports. In addition, we review promising hypotheses, that warrant consideration in future studies.

Recent Findings Associations between molecular characteristics of CRC have been published in relation to smoking, alcohol consumption; body mass index (BMI); waist:hip ratio; adult attained height; physical activity; early life energy restriction; dietary acrylamide, fiber, fat, methyl donors, omega 3 fatty acids; meat, including total protein, processed meat, and heme iron; and fruit and vegetable intake.

Summary MPE studies help identify where associations between diet, lifestyle, and CRC risk may otherwise be masked and also shed light on how timing of exposure can influence etiology. Sample size is often an issue, but this may be addressed in the future by pooling data.
\end{abstract}

Keywords Colorectal cancer $\cdot$ Molecular pathological epidemiology $\cdot$ Diet $\cdot$ Lifestyle $\cdot$ Review

\section{Introduction}

Colorectal cancer (CRC) is the third most common cancer in the world, regardless of sex, with nearly 1.4 million cases diagnosed in 2012 [1]. The majority of these cancers (70$80 \%$ ) are sporadic in nature [2], and if current trends continue, it is estimated that 2.2 million cases of CRC will be diagnosed

This article is part of the Topical Collection on Nutrition and Nutritional Interventions in Colorectal Cancer

Matty P. Weijenberg

mp.weijenberg@maastrichtuniversity.nl

1 Department of Epidemiology, GROW School for Oncology and Developmental Biology, Maastricht University, Maastricht, the Netherlands

2 Department of Pathology, GROW School for Oncology and Developmental Biology, Maastricht University Medical Centre, Maastricht, the Netherlands annually worldwide by 2030 [1]. It is now well accepted that CRC risk is highly modifiable through diet and lifestyle; recent reports suggest that up to $47 \%$ of CRC cases could be prevented by staying physically active, maintaining a healthy body weight and eating a healthy diet [3].

The expert panel of the World Cancer Research Fund (WCRF), which is the organization responsible for publishing the most comprehensive review to date on risk factors related to diet and physical activity for cancer, has recently concluded that there is convincing strong evidence that body fatness, adult attained height, and consuming processed meat and alcoholic drinks increase the risk of developing CRC, while physical activity decreases the risk of developing CRC. Furthermore, they concluded that consuming whole grains, foods containing dietary fiber, dairy products and calcium supplements probably protect against $\mathrm{CRC}$, and consuming red meat probably increases the risk of developing CRC [3].

$\mathrm{CRC}$ is not a single disease, but rather encompasses a heterogeneous complex of diseases characterized by numerous genetic and epigenetic abnormalities [4•]. Recently, several 
studies have used unsupervised clustering methods to develop genomic signatures to classify colorectal cancer (CRC) into different subtypes, and have shown that each subtype has distinct molecular features and prognosis [5•]. As summarized by Song et al. [5•], the CRC Assigner (CRCA) classifier categorized CRC into 5 distinct subtypes: enterocyte, gobletlike, inflammatory, stemlike, and transit amplifying (TA) [6]; and the Colon Cancer Subtypes (CCS) classifier identified 3 groups: CCS1, CCS2, and CCS3 [7]. Several studies have shown that different classifiers are highly correlated; for example, for CCS and CRCA classifiers, most CCS1 tumors are classified as TA or enterocyte, most CCS2 tumors are classified as inflammatory and gobletlike tumors, and most CCS3 tumors are classified as stemlike tumors [8•,9]. Although these classifications may be significant in the advancement of CRC research, these subtypes will not be specifically addressed in this review, as they have not yet been investigated in MPE studies yet.

Generally, there are different (epi)genetic pathways to CRC development, and the cancers resulting from each pathway have specific molecular characteristics that often associated with distinct prognosis trajectories. Therefore, it is also likely that these cancers have a distinct etiology. Diet and lifestyle factors may not only play a role in causing mutations and epigenetic changes, but also in enhancing tumor growth in tissues that have already acquired specific (epi) genetic aberrations. There may be direct causal associations between diet and lifestyle factors and molecular changes in CRC, and establishing this is important for prevention strategies, and increasing the ability to better predict disease progression and prognosis.

Traditionally, epidemiological research has been used to investigate how an exposure may increase or decrease the risk of developing cancer, and pathological research has been used to explore molecular characteristics of tumors to predict prognosis and response to treatment. By combining these two disciplines, a relatively new field of scientific investigation has emerged: molecular pathological epidemiology (MPE) [10]. In this review, we describe the (epi)genetic molecular pathways leading to CRC; identify MPE studies from around the world that have studied molecular markers of these pathways in relation to diet and/or lifestyle factors; summarize the data published on such associations; and explore future perspectives in this realm of research. We focus on diet and lifestyle factors for which there is evidence for an association with CRC as identified by the World Cancer Research Fund reports. In addition, we review promising tumor markers and hypotheses, that warrant consideration in future studies.

Studies on the importance of diet and lifestyle factors for CRC survival according to molecular subtype of CRC are not reviewed due to the current paucity of data. In addition, studies focused on downstream expression of genes in CRC as outcome are not reviewed.

\section{(Epi)genetic Pathways to CRC}

Although each individual CRC tumor is (epi) genetically complex, and arises and behaves in a unique manner, it is common to classify tumors according to a limited number of phenotypes, because it is assumed that tumors with similar molecular characteristics have arisen through common mechanisms [10].

There are two morphologic, multi-step pathways to CRC (the traditional adenoma-carcinoma pathway and the serrated neoplasia pathway), which are driven by three molecular carcinogenesis pathways (chromosomal instability (CIN), microsatellite instability (MSI), and epigenetic instability (primarily the $\mathrm{CpG}$ island methylator phenotype (CIMP)) [11•]. It is important to understand these pathways, because MPE studies have been used to identify disease subtypes that may benefit from certain behavioral interventions, and may be used to validate molecular markers for risk assessment, early detection, prognosis, and prediction $[12 \cdot \bullet, 13]$.

\section{The Traditional Adenoma-Carcinoma Pathway}

Tumors arising via the traditional adenoma-carcinoma pathway begin as premalignant lesions comprising of conventional, tubular or tubulovillous adenomas [11•], and account for approximately $60-90 \%$ of sporadic CRCs [2]. They are characterized by $\mathrm{CIN}$, which describes a condition of aneuploidy that is caused by an accelerated rate of gains and losses of entire or large portions of the chromosome during cell division $[14,15]$. CIN is associated with inactivating mutations or losses in the Adenomatous Polyposis Coli $(A P C)$ tumor suppressor gene, which occurs as an early event in this sequence [16]. Mutations in the KRAS oncogene, as well as TP53, SMAD4, and PIK3CA genes are also frequently observed [2]. With CIN, there is an increased rate of heterozygosity, which may contribute to the inactivation of tumor suppressor genes or activation of tumor oncogenes [17]. Descriptively, tumors that arise from this pathway are more often associated with male sex, and observed in the distal colon [11•].

\section{Serrated Neoplasia Pathway}

Approximately $10-30 \%$ of sporadic CRC tumors arise via the serrated neoplasia pathway [11•] and have distinctly different histology compared to tumors derived from the traditional adenoma-carcinoma sequence. They are characterized by MSI, a form of genetic instability characterized by length alterations within simple repeated microsatellite sequences of DNA. This is the result of strand slippage during DNA replication, which is not repaired due to a defective postreplication mismatch repair system [18]. An early event of these tumors is mutation of the $B R A F$ proto-oncogene, which inhibits normal apoptosis of colonic epithelial cells [19]. The driving force of the serrated neoplasia pathway is the $\mathrm{CpG}$ methylator 
phenotype (CIMP), a form of epigenetic instability responsible for silencing a range of tumor suppressor genes, including MLH1 [2]. Loss of MLH1 is thought to cause microsatellite instability (MSI) and once $M L H 1$ is inactivated, the rate of progression to malignant transformation is rapid [19]. Descriptively, these tumors are more frequently associated with female sex, and are observed in the proximal colon [11•].

\section{Insights from the Cancer Genome Atlas Study}

The Cancer Genome Atlas study, a collaboration between the National Cancer Institute (NCI) and the National Human Genome Research Institute (NHGRI), has generated a comprehensive, multi-dimensional map of the key genomic changes in CRC [20]. As recently summarized by Bae et al. [11•], the Cancer Genome Atlas study reports that CIN and MSI are mutually exclusive. CIMP, on the other hand, overlaps with the MSI pathway because of sporadic MSI-high CRCs, which are also usually CIMP-high, but does not appear to be in an exclusive relationship with the CIN pathway [11 20]. CIMP-high tumors can exist in the absence of MSI-high, and these tumors show some copy number variations across the genome, but the degree of CIN is less pronounced than CIMP-negative, MSI-low tumors. This suggests that CIMP alone may not be enough for the malignant transformation of serrated polyps, and requires collaboration with either CIN or MSI to promote successful malignant transformation $[11 \cdot 20]$.

In an MPE paradigm, a potential etiological factor, such as diet or lifestyle, is assessed with risk of an outcome across strata of molecular characteristics for the disease of interest [12••]. For purposes of this review, focus is on MPE studies that have considered diet and lifestyle factors in conjunction with primary molecular markers of (epi)genetic instability. For the traditional adenoma-carcinoma pathway, these include CIN, APC mutation, KRAS mutation, and TP53 mutation. For the serrated neoplasia pathway, these include $B R A F \mathrm{mu}-$ tation, MSI, hypermethylation of $M L H 1$, and CIMP.

\section{MPE Studies on Diet, Lifestyle, and CRC}

Because MPE is an emerging research field, studies are usually drawn from existing cohort and case-control studies that have collected pathology specimens [12••]. In the realm of $\mathrm{CRC}$, it is not uncommon for some large, long-running, population-based studies to have thousands of CRC cases. However, obtaining tumor blocks and subsequently phenotyping molecular characteristics in sample numbers large enough for meaningful statistical analysis requires a significant investment of both time and money. Therefore, while many epidemiological studies have investigated associations between diet, lifestyle, and $\mathrm{CRC}$, the number of studies that have embarked on MPE investigations considering such associations is still currently quite limited.

\section{The Current Review}

We reviewed the literature by searching combinations of key words (molecular pathological epidemiology, prospective cohort study, case-control study, KRAS mutation, APC mutation, Microsatellite Instability, CpG Island Methylator Phenotype, CIMP, BRAF mutation) in Pubmed and EMBASE databases, as well as by analyzing proceedings and participants of the International Molecular Pathological Epidemiology Meeting Series. Eight prospective cohort studies, five case-control studies, and one cross-sectional study that explicitly presented data on molecular markers of (epi)genetic instability were identified (Table 1). However, one cohort study did not further consider associations with diet and lifestyle factors [71], so for purposes of this review, was excluded from discussion. Of the remaining studies, associations have been published on molecular endpoints of CRC in relation to smoking, alcohol consumption; body mass index (BMI); waist:hip ratio; adult attained height; physical activity; early life energy restriction; ethnicity; dietary acrylamide, fiber, fat, methyl donors, omega 3 fatty acids; meat intake, including total protein, processed meat, and heme iron; and vegetable intake. For purposes of comparison and discussion, statistical associations are summarized in Tables 2 and 3, according to markers of the traditional adenoma-carcinoma and serrated neoplasia pathways, respectively, and the impact of these findings on advancing knowledge of CRC etiology is described in further detail below.

\section{Smoking}

Smoking has been studied in relation to both the traditional adenoma-carcinoma pathway $[25,41,42,58,70,72]$ and the serrated neoplasia pathway $[30,58,60-62,65]$. As described in the proceedings of the third international MPE meeting, smoking provides one of the best examples of how MPE research can better predict CRC compared to epidemiological studies without molecular classification [12••]. Meta-analysis of traditional epidemiological studies showed only a modest link between smoking and CRC (i.e., a RR usually below 1.2) [73], which may lead one to believe that smoking is not a convincing risk factor for CRC. However, with the advent of MPE, it can be seen that once CRC cases are stratified by MSI or CIMP status, this risk increases up to two-fold for MSI-H and CIMP-H tumors in prospective cohort studies, while there are null associations for tumors not exhibiting these phenotypes (i.e., tumors of the traditional adenoma-carcinoma pathway). These data supports the premise that traditional epidemiological studies may mask true associations between some 
Table 1 Epidemiological studies that have collected molecular data according to (epi)genetic characteristics of colorectal cancer

\begin{tabular}{|c|c|c|c|}
\hline Study & Country & $N$ & Tumor characteristics \\
\hline \multicolumn{4}{|l|}{ Prospective cohort studies } \\
\hline $\begin{array}{l}\text { European Prospective Investigation into } \\
\text { Cancer (EPIC) Norfolk [21-24] }\end{array}$ & England & 30,441 & $\begin{array}{l}A P C \text { mutation and promoter hypermethylation, } \\
B R A F \text { mutation, } K R A S \text { mutation, } M L H 1 \\
\text { promoter hypermethylation, TP53 mutation }\end{array}$ \\
\hline Iowa Women's Health Study (IWHS) [25-29] & USA & 41,836 & $B R A F$ mutation, CIMP, KRAS mutation, MSI \\
\hline $\begin{array}{l}\text { Health Professionals Follow-up Study } \\
{[10,30-37]}\end{array}$ & USA & 173,229 & $\begin{array}{l}\text { BRAF mutation, CIMP, KRAS mutation, LINE-1 } \\
\text { hypomethylation, MSI, PIK3CA mutation }\end{array}$ \\
\hline Malmo Diet and Cancer Study (MDCS) [26] & Sweden & 29,098 & $B R A F$ mutation, $K R A S$ mutation, MSI \\
\hline $\begin{array}{l}\text { Melbourne Collaborative Cohort Study (MCCS) } \\
{[38,39 \bullet, 40]}\end{array}$ & Australia & 41,328 & $B R A F$ mutation, CIMP, MSI \\
\hline $\begin{array}{l}\text { Netherlands Cohort Study on Diet and Cancer } \\
\text { (NLCS) }[39 \bullet, 41-50,51 \cdot, 52-55]\end{array}$ & Netherlands & 120,852 & $\begin{array}{l}A P C \text { mutation, CIMP, CIN, BRAF mutation, KRAS } \\
\text { mutation, } M G M T \text { promotor hypermethylation, } \\
\text { MLH1 promoter hypermethylation, MSI, }\end{array}$ \\
\hline Nurses Health Study (NHS) $[10,30-37,56,57]$ & USA & 77,443 & $\begin{array}{l}\text { BRAF mutation, CIMP, KRAS mutation, LINE-1 } \\
\text { hypomethylation, MSI, PIK3CA mutation }\end{array}$ \\
\hline Swedish Health and Disease Study (SHDS) $[58]^{1}$ & Sweden & 166,414 & CIMP, MSI \\
\hline \multicolumn{4}{|l|}{ Case-control studies } \\
\hline $\begin{array}{l}\text { Colorectal Cancer: Chances for Prevention } \\
\text { Through Screening (DACHS) [59] }\end{array}$ & Germany & 1215 cases/ 1891 controls & MSI \\
\hline $\begin{array}{l}\text { Kaiser Permanente Medical Care Program of } \\
\text { Northern California (KPMCP) and the state } \\
\text { of Utah/Minnesota [60-64] }\end{array}$ & USA & 1510 cases/ 2410 controls & $\begin{array}{l}A P C \text { mutation, } B R A F \text { mutation, CIMP, } K R A S \\
\text { mutation, MSI, TP53 mutation }\end{array}$ \\
\hline Colon Cancer Family Registry (CCFR) [65] & USA & 2253 cases/ 4486 controls & MSI \\
\hline Dutch case-control study [66-68] & Netherlands & 278 cases/ 414 controls & $\begin{array}{l}M L H 1 \text { promoter hypermethylation, MSI, } A P C \\
\text { mutation, }\end{array}$ \\
\hline Majorca case-control study [69] & Spain & 286 cases/295 controls & KRAS mutation \\
\hline \multicolumn{4}{|l|}{ Cross-sectional studies } \\
\hline Martinez et al. [70] & Spain & 623 & $A P C$ mutation, $K R A S$ mutation \\
\hline
\end{tabular}

One study did not publish data on these molecular endpoints with respect to diet and lifestyle factors

risk factors and cancer, and that MPE studies can shed light on true patterns of association.

\section{Alcohol Intake}

The association between alcohol intake and $\mathrm{CRC}$ has been studied separately by tumor markers related to the traditional carcinoma-adenoma pathway $[21,38,43,66]$ and the serrated neoplasia pathway $[22,38,44,63,67]$. Although considered by the WCRF as a convincing risk factor for CRC in menand women, MPE data is conflicting. Acetaldehyde in alcoholic beverages is a highly toxic substance that is carcinogenic to humans. In one of the earliest case-control studies considering alcohol in relation to risk of $A P C$ mutations, Diergaarde et al. found that alcohol intake only increased the risk of $A P C$ wildtype tumors [66]. In 2006, Bongaerts et al. concluded that alcohol was not associated with tumors harboring mutations in the KRAS gene [43]; however, in 2016, Jayasekra et al. concluded that alcohol intake is associated with an increased risk of $K R A S$ mutated and $B R A F$ wildtype/KRAS wildtype tumors originating via the traditional adenoma-carcinoma pathway but not with $B R A F$ mutated tumors originating via the serrated pathway [38]. This is in contrast to case-control data from Slattery et al., who was the first to report that alcohol intake is associated with MSI [63]. Some reasons for these discrepancies may include heterogeneity between the way that alcohol intake was measured (i.e. lifetime exposure, highest vs. lowest intake, continuous intake), and the inability to consider men and women separately in data analysis due to limitations with sample size. Another layer of complexity in the association between alcohol and CRC risk is that there are susceptibility genes in relation to alcohol metabolism not accounted for in MPE studies. This may also explain some of the observed heterogeneity.

\section{Indicators of Energy Balance}

Indicators of energy balance include lifestyle factors that play a role in the development of body growth and obesity. These include body mass index (BMI), waist and hip circumference, adult-attained height, caloric intake and physical activity. The majority of MPE research on these factors has been conducted 


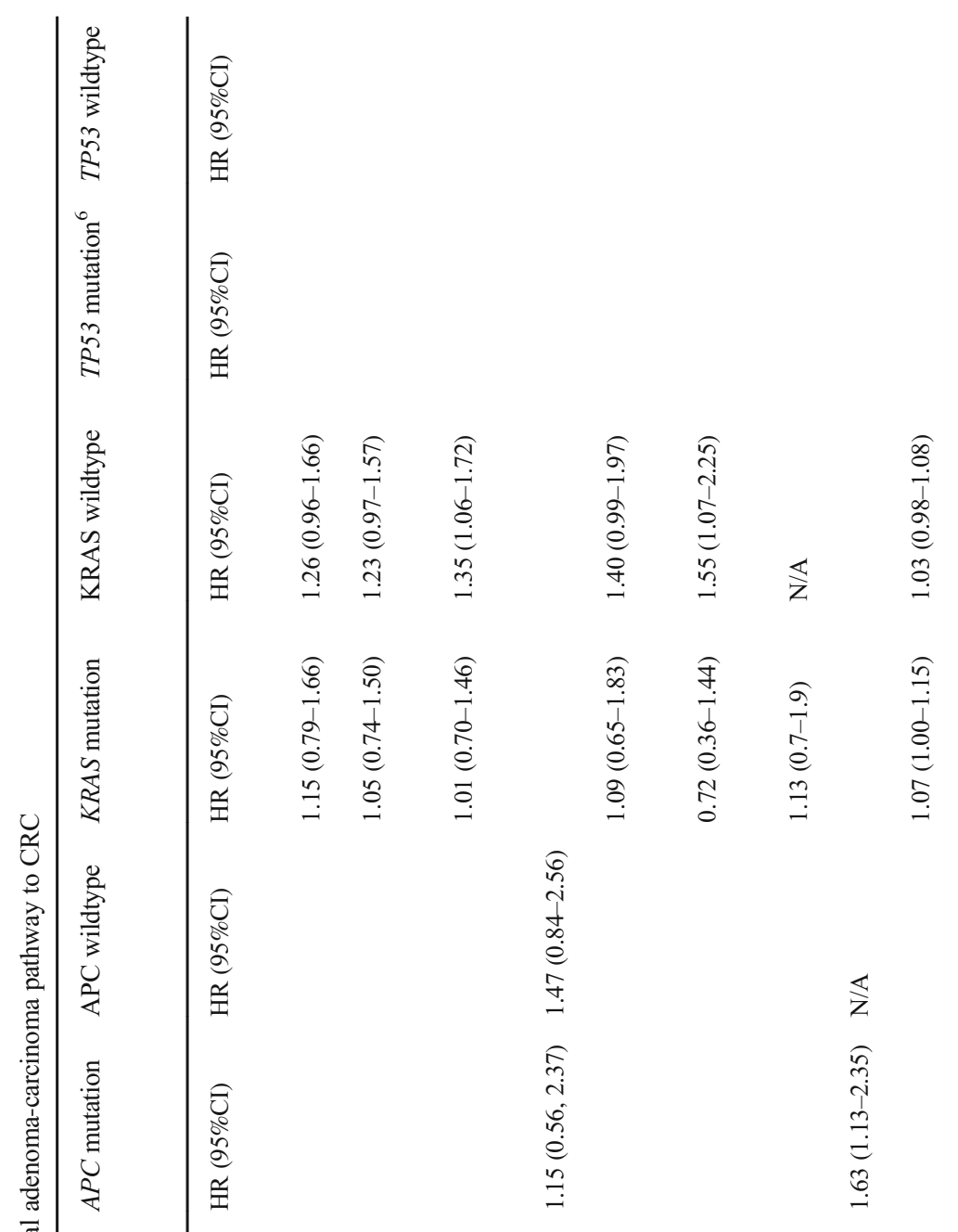

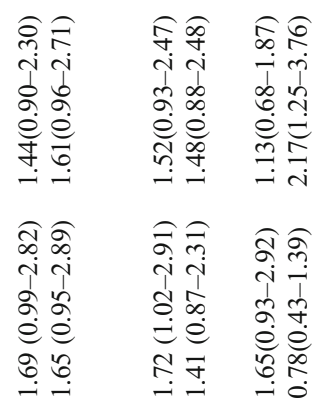
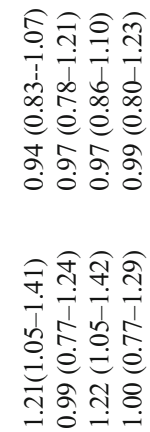

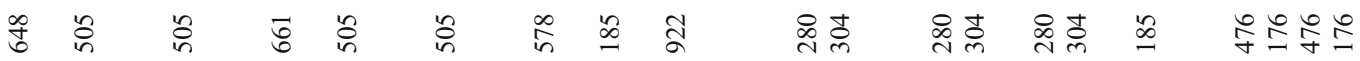

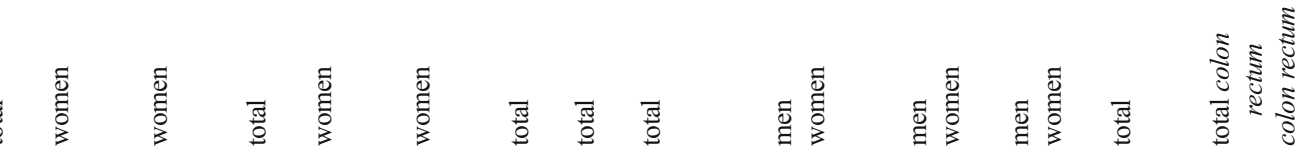

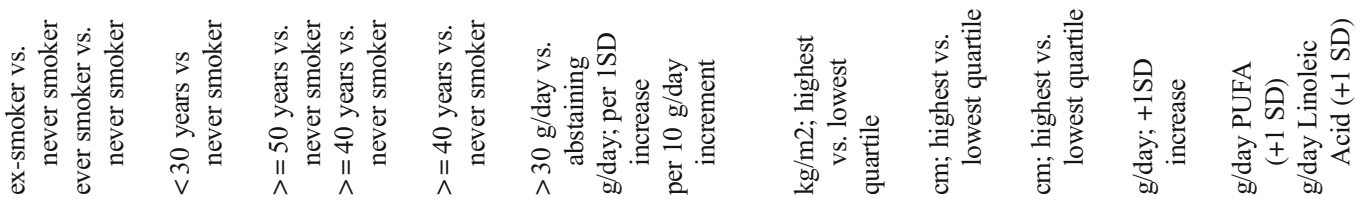

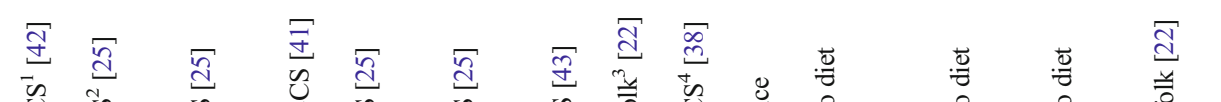




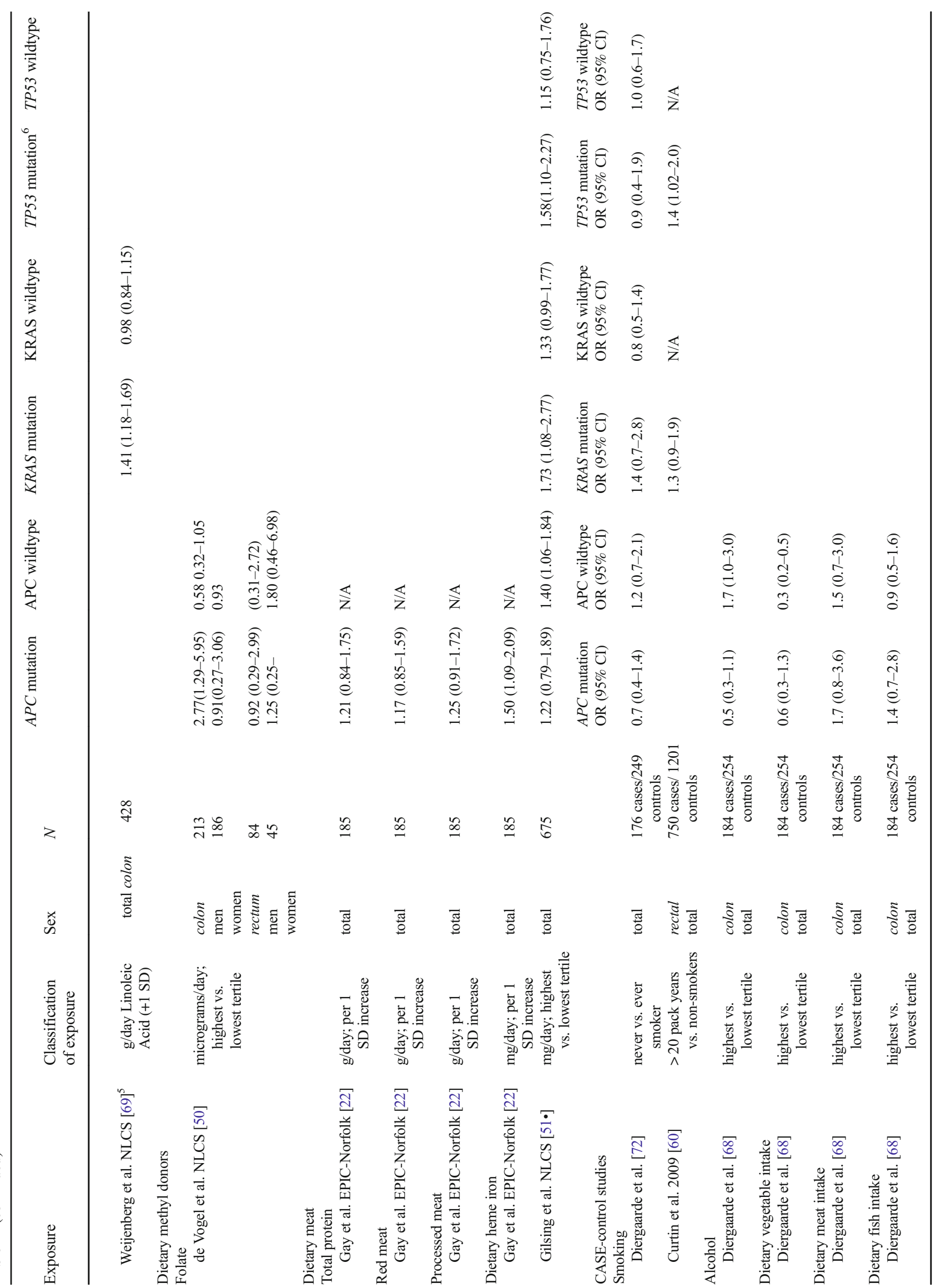


with respect to markers of the serrated neoplasia pathway [26, 39•, 45, 46, 59, 62, 64]. Although associations with $A P C$, $K R A S$, and CIN have not been directly considered, the fact that BMI and waist measurements are positively associated with $B R A F$ mutations and $B R A F$-wildtype, MSI and microsatellite stable tumors, and CIMP-H and non-CIMP tumors, is in accordance with WCRF evidence showing that overweight is a strong risk factor for $\mathrm{CRC}$ in general.

On the other hand, studies on adult-attained height and early life energy restriction suggest that timing of exposure may be important for influencing CRC risk. Height is a marker of aggregated fetal and childhood experience, and can be considered a proxy measure for important nutritional exposures, which affect several hormonal and metabolic axes [3]. Like body weight, adult-attained height is also an established risk factor for CRC in general; however, observations tend to be stronger for tumors demonstrating $B R A F$ mutation and MSI $[39 \bullet, 45]$. One study on early life energy restriction showed that exposure to famine during childhood and adolescence decreased the risk of developing a tumor characterized by CIMP [46]. Taken together, this suggests that early life exposures may influence risk of epigenetic instability and CRC risk through the serrated neoplasia pathway, but data are scarce and more research is needed in this area.

\section{Dietary Factors}

Because the majority of MPE studies are derived from larger cohort and case-control studies that were designed to consider outcomes between diet and cancer, and therefore have validated food frequency questionnaires in place, it is not uncommon for multiple dietary exposures to be presented in the same publication.

Red meat intake was identified by the WCRF as a probable risk factor for CRC, and MPE research supports that this may especially be true for tumors of the traditional adenomacarcinoma pathway; dietary heme intake shows stronger associations with KRAS.mutated tumors than KRAS wildtype tumors. It has been hypothesized that heme can enhance the endogenous formation of carcinogenic $N$-nitroso compounds [51•]. The study by Gilsing et al. is important because it is the first human observational study providing evidence, as expected, for an association between heme and tumors with specific point mutations [51•].

Similarly, the first observational study showing that dietary acrylamide might be associated with CRC with specific somatic mutations, such as $\mathrm{G}>\mathrm{C}$ or $\mathrm{G}>\mathrm{T}$ mutations, was recently published [47], which supports the a priori hypothesis that metabolites of acrylamide are human carcinogens.

With respect to dietary fat, a high intake of polyunsaturated fat, in particular linoleic acid, has also been linked to KRAS mutations [49]. Intriguingly, and in contrast, it was recently reported that high marine omega-3 polyunsaturated fatty acid 


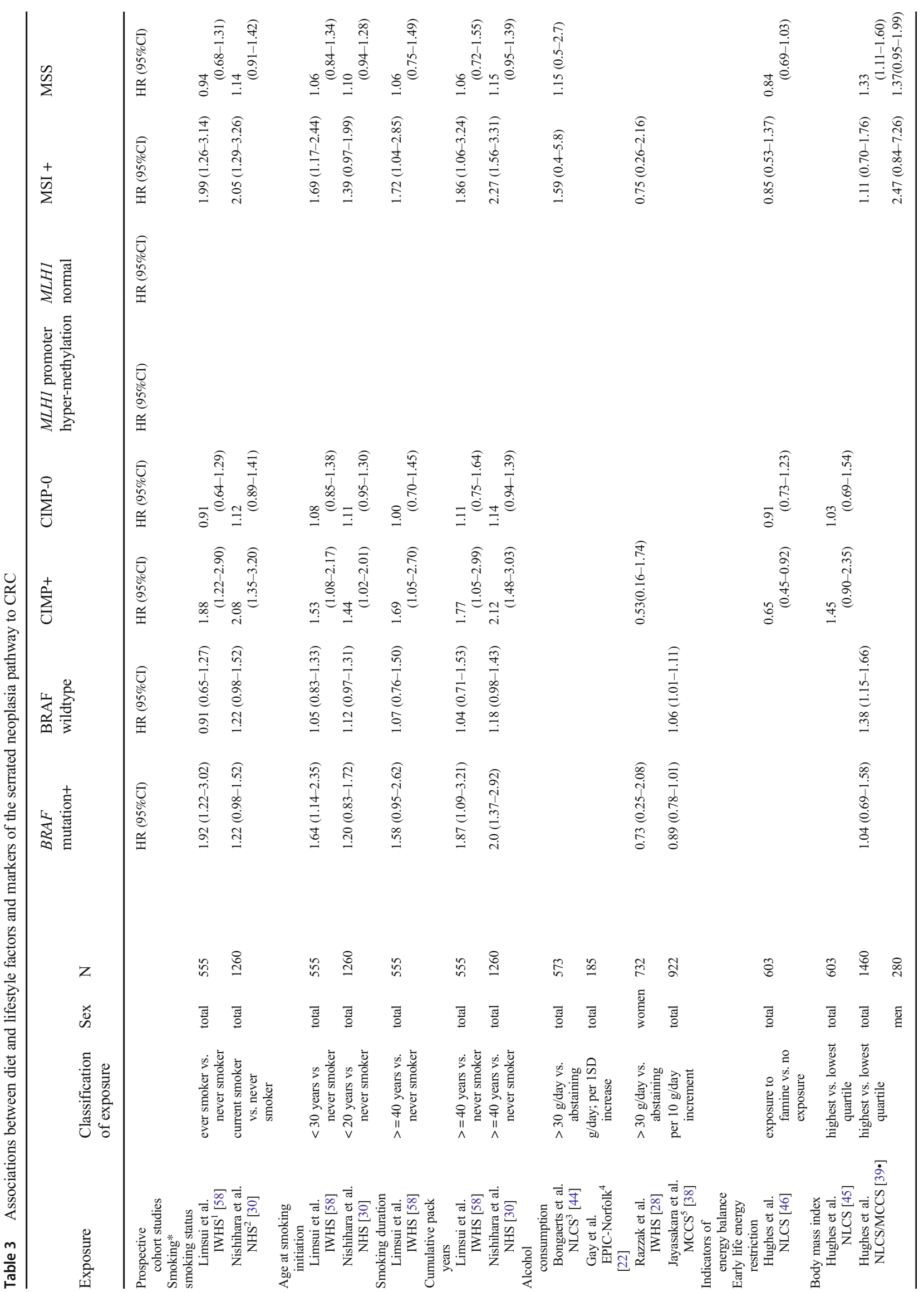




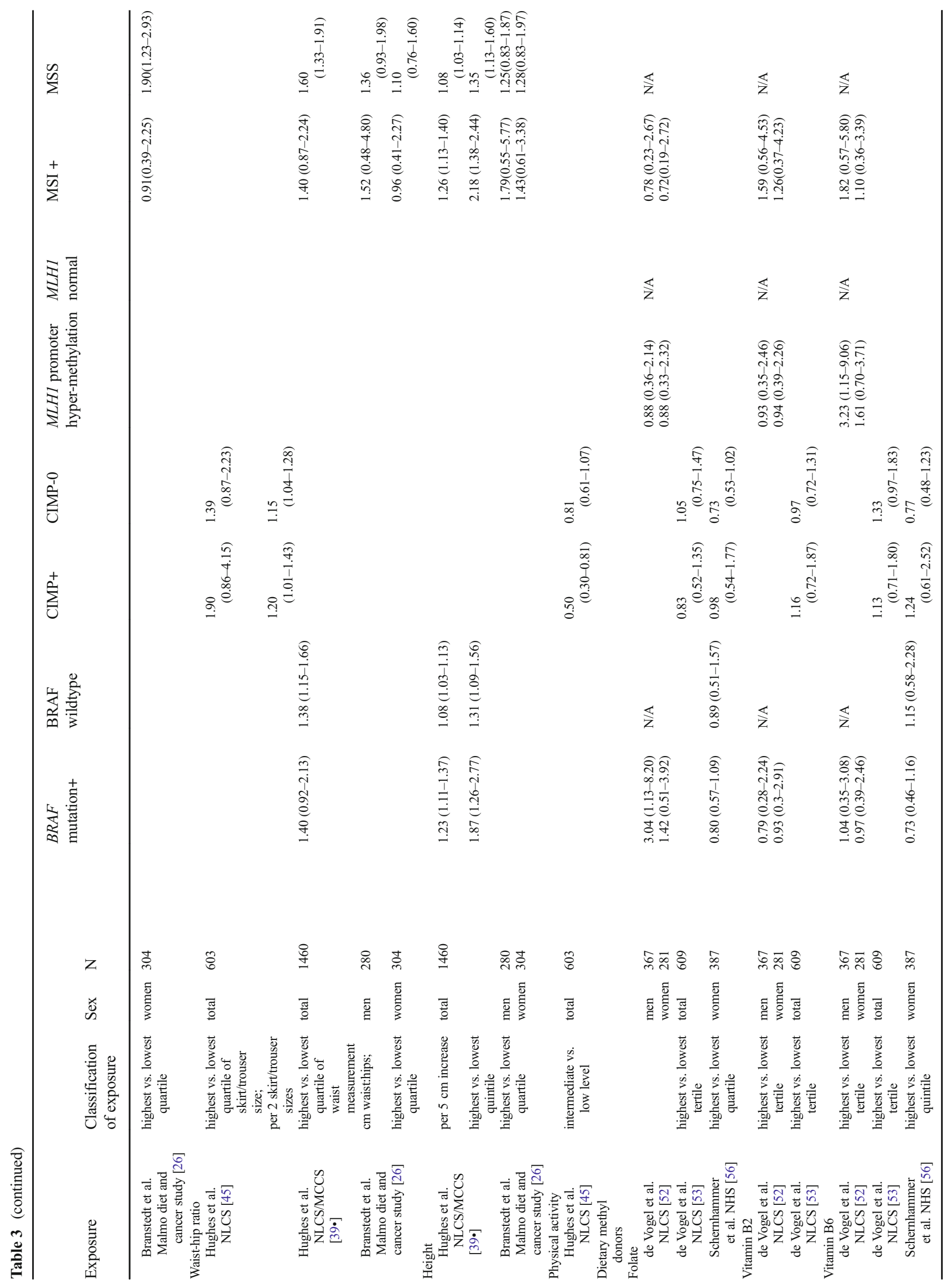




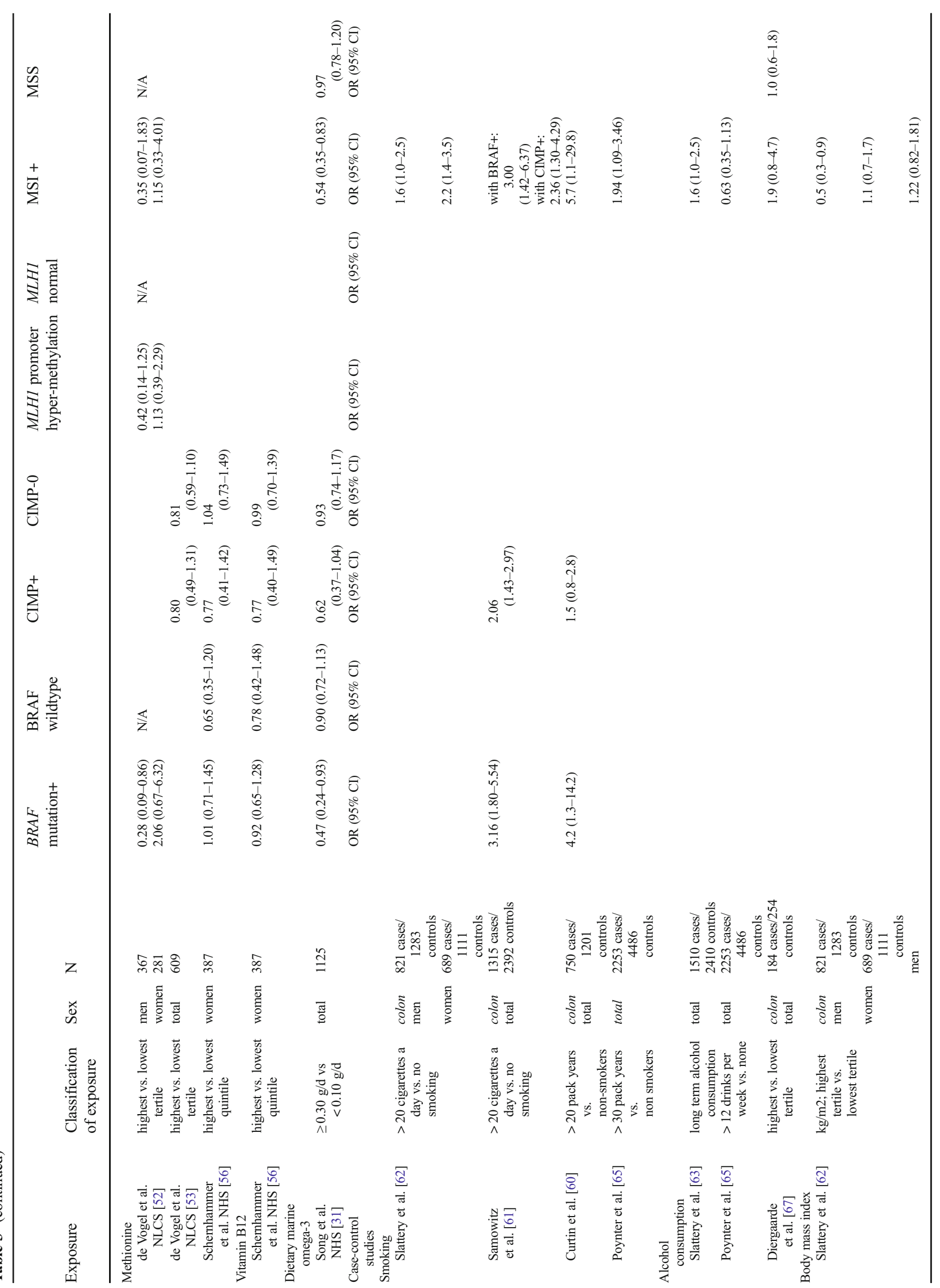




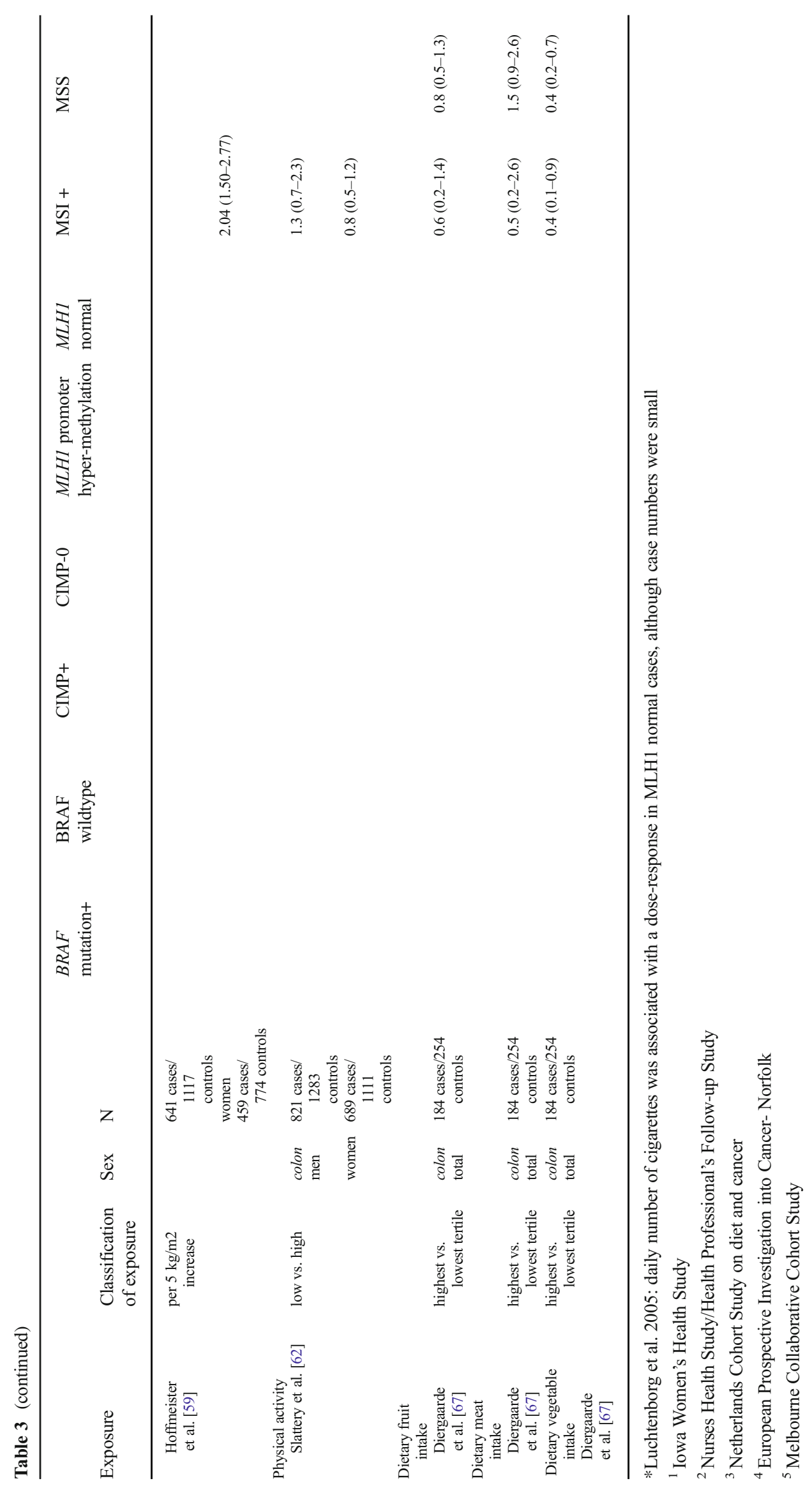


intake is associated with lower risk of MSI-high CRC but not MSS tumors, suggesting a potential role of omega- 3 fatty acids in protection against $\mathrm{CRC}$ through DNA mismatch repair [31]. Calcium, milk, and garlic were not significantly associated with specific tumor subtypes in the reviewed publications [21, 22, 63, 64, 51•].

Alcohol is often considered in conjunction with dietary methyl donors such as folate, because folate may influence promoter methylation at gene promoters, and is depleted with alcohol intake. It has been hypothesized that methyl donors such as folate and methionine influence CRC through the serrated neoplasia pathway because of their role in methyl transport (i.e. a deficient status may result in a decrease in promotor hyper methylation, as observed in CIMP). Folate intake is associated with $B R A F$ mutations, suggesting that it does play a role in epigenetic aberrations [52]. However, high folate consumption also appears to reduce the risk of $A P C$ wildtype colon tumors, while being positively associated with $A P C$ mutated colon tumors in men [50], indicating that folate may also enhance colorectal carcinogenesis through a distinct $A P C$ mutated pathway. More research, with attention to sample size, is needed to replicate and clarify these associations.

\section{Future Perspectives}

In order to gain more insight into etiology and potential CRC interventions, it is important to continue investigating associations between diet, lifestyle factors and risk of different CRC subtypes. As mentioned previously, several studies have recently been publishing clustering CRC into specific subtypes $[5 \bullet, 6$, 8•, 9, 74]. The Cancer Genome Atlas study provides additional insights on how MPE studies in the realm of CRC should consider molecular markers and etiologic pathways [20].

As noted earlier, MPE studies are usually drawn from existing cohort and case-control studies. That means that in most cases, such studies have validated food-frequency and lifestyle questionnaires in place and in the future may have more tumor tissues available for molecular subtyping as cases continue to be identified. This will improve interpretation of research findings as One important limitations of MPE studies is limited sample size. Any molecular pathological epidemiology study conducted within a larger cohort will undergo multiple exclusions based on availability of tumor material and valid assay results. Therefore, the sample size for a study with molecular endpoints will always be smaller than the parent study. To analyze molecular data for associations with diet and lifestyle factors, a subset analysis for the different sub-sets is performed (i.e. CIMP-H vs CIMP-0; MSI-H vs MSS; $B R A F$ mutated vs. $B R A F$ wildtype tumors). The sample size for a subset, especially the rarer event (e.g., CIMP-H, MSI-H, $B R A F$ mutated) may be too small to provide adequate statistical power, or limit the number of possible subtypes to be distinguished, even though this may at least in part be offset by more refined risk estimates in these subtypes.

Pooling data from independent studies may be a solution to this problem. To our knowledge, only one such MPE pooling data from the (NLCS) and the Melbourne Collaborative Cohort Study (MCCS) to assess the association between body size and CRC, by MSI and BRAF mutation, has been published so far. However, iin that study, pooling CIMP data was not possible due to methodological differences [39•]. This study highlights a unique challenge of pooling molecular data: it is important that similar definitions and laboratory analyses be used to define the phenotype in each study. We have previously published on the need for a global consensus on how to analyze and define CIMP [75, 76], but this is important for all molecular endpoints.

In a 2010 review on MPE of CRC, Ogino et al. identified that to overcome the unique challenges of this work, it would be necessary to coordinate research efforts around the world and to formulate a system where researchers could discover and validate new findings [4•]. Recently, The 3rd International Molecular Pathological Epidemiology (MPE) Meeting was held in Boston, which was attended by 150 scientists from 17 different countries [12••]. This meeting highlighted a new wave of research that is focused on increasing the understanding of the role that lifestyle/behavioral factors on modifying prognosis of diseases (including CRC) by considering specific disease subtypes. Such organization and collaboration will only expedite the creation of new, high quality studies, research questions, and answers around CRC etiology.

\section{Conclusion}

Because $\mathrm{CRC}$ is a heterogeneous disease with several molecular subtypes, traditional epidemiological studies may mask completely or underestimate true associations between diet, lifestyle and disease risk. The WCRF has identified several convincing and probable risk factors for $\mathrm{CRC}$, and by utilizing MPE can inform prevention and treatment strategies as well as predict prognosis for CRC.

MPE studies have also suggested that timing of exposure may be important for establishing patterns of epigenetic instability (e.g., as suggested by associations on adult-attained height and early life energy restriction with tumors exhibiting specific (epi)genetic markers). Furthermore, MPE studies offer the possibility to test hypotheses with regards to mutagenic effects (e.g., as suggested by the associations of heme iron and acrylamide with tumors exhibiting specific somatic mutations related to the exposure).

In the future, continuing collaboration and pooling data from high quality studies, including data on other molecular endpoints, may improve the strength of individual MPE 
findings, overcome the challenges of small sample sizes, and further pinpoint carcinogenic mechanisms leading to CRC.

Open Access This article is distributed under the terms of the Creative Commons Attribution 4.0 International License (http:// creativecommons.org/licenses/by/4.0/), which permits unrestricted use, distribution, and reproduction in any medium, provided you give appropriate credit to the original author(s) and the source, provide a link to the Creative Commons license, and indicate if changes were made.

\section{References}

Papers of particular interest, published recently, have been highlighted as:

- Of importance

•- Of major importance

1. Arnold M, Sierra MS, Laversanne M, Soerjomataram I, Jemal A, Bray F. Global patterns and trends in colorectal cancer incidence and mortality. Gut. 2017;66(4):683-91. https://doi.org/10.1136/ gutjnl-2015-310912.

2. Muller MF, Ibrahim AE, Arends MJ. Molecular pathological classification of colorectal cancer. Virchows Arch. 2016;469(2):12534. https://doi.org/10.1007/s00428-016-1956-3.

3. World Cancer Research Fund/American Institute for Cancer Research. Continuous Update Project Report: Diet, Nutrition, Physical Activity and Colorectal Cancer. 2017. Available at: wcrf.

4. Ogino S, Chan AT, Fuchs CS, Giovannucci E. Molecular pathological epidemiology of colorectal neoplasia: an emerging transdisciplinary and interdisciplinary field. Gut. 2011;60(3):397-411. https://doi.org/10.1136/gut.2010.217182. This article coined the field of molecular pathological epidemiology

5. Song N, Pogue-Geile KL, Gavin PG, Yothers G, Kim SR, Johnson NL, et al. Clinical Outcome From Oxaliplatin Treatment in Stage II/III Colon Cancer According to Intrinsic Subtypes: Secondary Analysis of NSABP C-07/NRG Oncology Randomized Clinical Trial. JAMA Oncol. 2016;2(9):1162-9. https://doi.org/10.1001/jamaoncol.2016. 2314. This article identifies recent advancements in CRC subtyping, which could influence future MPE study designs, leading to even more accurate prediction of risk.

6. Sadanandam A, Lyssiotis CA, Homicsko K, Collisson EA, Gibb WJ, Wullschleger S, et al. A colorectal cancer classification system that associates cellular phenotype and responses to therapy. Nat Med. 2013;19(5):619-25. https://doi.org/10.1038/nm.3175.

7. de Sousa E, Walter LT, Higa GS, Casado OA, Kihara AH. Developmental and functional expression of miRNA-stability related genes in the nervous system. PLoS One. 2013;8(5):e56908. https://doi.org/10.1371/journal.pone.0056908.

8. Guinney J, Dienstmann R, Wang X, de Reynies A, Schlicker A, Soneson C, et al. The consensus molecular subtypes of colorectal cancer. Nat Med. 2015;21(11):1350-6. https://doi.org/10.1038/nm. 3967. This summarizes recent advancements in CRC subtyping, which could influence future MPE study designs, leading to even more accurate prediction of risk.

9. Sadanandam A, Wang X, de Sousa EMF, Gray JW, Vermeulen L, Hanahan D, et al. Reconciliation of classification systems defining molecular subtypes of colorectal cancer: interrelationships and clinical implications. Cell Cycle. 2014;13(3):353-7. https://doi.org/10. 4161/cc.27769.
10. Ogino S, Stampfer M. Lifestyle factors and microsatellite instability in colorectal cancer: the evolving field of molecular pathological epidemiology. J Natl Cancer Inst. 2010;102(6):365-7. https://doi. org/10.1093/jnci/djq031.

11. Bae JM, Kim JH, Kang GH. Molecular subtypes of colorectal cancer and their clinicopathologic features, with an emphasis on the serrated neoplasia pathway. Arch Pathol Lab Med. 2016;140(5): 406-12. https://doi.org/10.5858/arpa.2015-0310-RA. This article summarizes recent advancements in CRC subtyping, which could influence future MPE study designs, leading to even more accurate prediction of risk.

12.• Campbell PT, Rebbeck TR, Nishihara R, Beck AH, Begg CB, Bogdanov AA, et al. Proceedings of the third international molecular pathological epidemiology (MPE) meeting. Cancer Causes Control. 2017;28(2):167-76. https://doi.org/10.1007/s10552-0160845-z. This article highlighted a new wave of MPE research that is focused on increasing the understanding of the role that lifestyle/behavioural factors on modifying prognosis.

13. Ogino S, Nishihara R, VanderWeele TJ, Wang M, Nishi A, Lochhead P, et al. Review article: the role of molecular pathological epidemiology in the study of neoplastic and non-neoplastic diseases in the era of precision medicine. Epidemiology. 2016;27(4): 602-11. https://doi.org/10.1097/EDE.0000000000000471.

14. Rajagopalan H, Nowak MA, Vogelstein B, Lengauer C. The significance of unstable chromosomes in colorectal cancer. Nat Rev Cancer. 2003;3(9):695-701. https://doi.org/10.1038/nrc1165.

15. Sieber OM, Heinimann K, Tomlinson IP. Genomic instability - the engine of tumorigenesis? Nat Rev Cancer. 2003;3(9):701-8. https:// doi.org/10.1038/nrc1170.

16. Derks S, Postma C, Carvalho B, van den Bosch SM, Moerkerk PT, Herman JG, et al. Integrated analysis of chromosomal, microsatellite and epigenetic instability in colorectal cancer identifies specific associations between promoter methylation of pivotal tumour suppressor and DNA repair genes and specific chromosomal alterations. Carcinogenesis. 2008;29(2):434-9. https://doi.org/10.1093/ carcin/bgm270.

17. Hermsen M, Postma C, Baak J, Weiss M, Rapallo A, Sciutto A, et al. Colorectal adenoma to carcinoma progression follows multiple pathways of chromosomal instability. Gastroenterology. 2002;123(4):1109-19. https://doi.org/10.1053/gast.2002.36051.

18. Imai K, Yamamoto H. Carcinogenesis and microsatellite instability: the interrelationship between genetics and epigenetics. Carcinogenesis. 2008;29(4):673-80. https://doi.org/10.1093/ carcin/bgm228.

19. Snover DC. Update on the serrated pathway to colorectal carcinoma. Hum Pathol. 2011;42(1):1-10. https://doi.org/10.1016/j. humpath.2010.06.002.

20. Cancer Genome Atlas N. Comprehensive molecular characterization of human colon and rectal cancer. Nature. 2012;487(7407): 330-7. https://doi.org/10.1038/nature11252.

21. Gay LJ, Mitrou PN, Keen J, Bowman R, Naguib A, Cooke J, et al. Dietary, lifestyle and clinicopathological factors associated with APC mutations and promoter methylation in colorectal cancers from the EPIC-Norfolk study. J Pathol. 2012;228(3):405-15. https://doi.org/10.1002/path.4085.

22. Gay LJ, Arends MJ, Mitrou PN, Bowman R, Ibrahim AE, Happerfield L, et al. MLH1 promoter methylation, diet, and lifestyle factors in mismatch repair deficient colorectal cancer patients from EPIC-Norfolk. Nutr Cancer. 2011;63(7):1000-10. https://doi. org/10.1080/01635581.2011.596987.

23. Naguib A, Mitrou PN, Gay LJ, Cooke JC, Luben RN, Ball RY, et al. Dietary, lifestyle and clinicopathological factors associated with $\mathrm{BRAF}$ and $\mathrm{K}$-ras mutations arising in distinct subsets of colorectal cancers in the EPIC Norfolk study. BMC Cancer. 2010;10(1):99. https://doi.org/10.1186/1471-2407-10-99. 
24. Park JY, Mitrou PN, Keen J, Dahm CC, Gay LJ, Luben RN, et al. Lifestyle factors and p53 mutation patterns in colorectal cancer patients in the EPIC-Norfolk study. Mutagenesis. 2010;25(4): 351-8. https://doi.org/10.1093/mutage/geq012.

25. Samadder NJ, Vierkant RA, Tillmans LS, Wang AH, Lynch CF, Anderson KE, et al. Cigarette smoking and colorectal cancer risk by KRAS mutation status among older women. Am J Gastroenterol. 2012;107(5):782-9. https://doi.org/10.1038/ajg.2012.21.

26. Brandstedt J, Wangefjord S, Borgquist S, Nodin B, Eberhard J, Manjer J, et al. Influence of anthropometric factors on tumour biological characteristics of colorectal cancer in men and women: a cohort study. J Transl Med. 2013;11(1):293. https://doi.org/10. 1186/1479-5876-11-293.

27. Brandstedt J, Wangefjord S, Nodin B, Eberhard J, Jirstrom K, Manjer J. Associations of hormone replacement therapy and oral contraceptives with risk of colorectal cancer defined by clinicopathological factors, beta-catenin alterations, expression of cyclin D1, p53, and microsatellite-instability. BMC Cancer. 2014;14(1):371. https://doi.org/10.1186/1471-2407-14-371.

28. Razzak AA, Oxentenko AS, Vierkant RA, Tillmans LS, Wang AH, Weisenberger DJ, et al. Alcohol intake and colorectal cancer risk by molecularly defined subtypes in a prospective study of older women. Cancer Prev Res. 2011;4(12):2035-43. https://doi.org/10.1158/ 1940-6207.CAPR-11-0276.

29. Limburg PJ, Limsui D, Vierkant RA, Tillmans LS, Wang AH, Lynch CF, et al. Postmenopausal hormone therapy and colorectal cancer risk in relation to somatic KRAS mutation status among older women. Cancer Epidemiol Biomark Prev. 2012;21(4):6814. https://doi.org/10.1158/1055-9965.EPI-11-1168.

30. Nishihara R, Morikawa T, Kuchiba A, Lochhead P, Yamauchi M, Liao X, et al. A prospective study of duration of smoking cessation and colorectal cancer risk by epigenetics-related tumor classification. Am J Epidemiol. 2013;178(1):84-100. https://doi.org/10. 1093/aje/kws431.

31. Song M, Nishihara R, Wu K, Qian ZR, Kim SA, Sukawa Y, et al. Marine omega-3 polyunsaturated fatty acids and risk of colorectal cancer according to microsatellite instability. J Natl Cancer Inst. 2015;107(4) https://doi.org/10.1093/jnci/djv007.

32. Lee JE, Baba Y, Ng K, Giovannucci E, Fuchs CS, Ogino S, et al. Statin use and colorectal cancer risk according to molecular subtypes in two large prospective cohort studies. Cancer Prev Res. 2011;4(11):1808-15. https://doi.org/10.1158/1940-6207.CAPR11-0113.

33. Liao X, Lochhead P, Nishihara R, Morikawa T, Kuchiba A, Yamauchi M, et al. Aspirin use, tumor PIK3CA mutation, and colorectal-cancer survival. N Engl J Med. 2012;367(17):1596606. https://doi.org/10.1056/NEJMoa1207756.

34. Morikawa T, Kuchiba A, Lochhead P, Nishihara R, Yamauchi M, Imamura Y, et al. Prospective analysis of body mass index, physical activity, and colorectal cancer risk associated with beta-catenin (CTNNB1) status. Cancer Res. 2013;73(5):1600-10. https://doi. org/10.1158/0008-5472.CAN-12-2276.

35. Nishihara R, Lochhead P, Kuchiba A, Jung S, Yamauchi M, Liao X, et al. Aspirin use and risk of colorectal cancer according to BRAF mutation status. JAMA. 2013;309(24):2563-71. https://doi.org/10. 1001/jama.2013.6599.

36. Nishihara R, Wang M, Qian ZR, Baba Y, Yamauchi M, Mima K, et al. Alcohol, one-carbon nutrient intake, and risk of colorectal cancer according to tumor methylation level of IGF2 differentially methylated region. Am J Clin Nutr. 2014;100(6):1479-88. https:// doi.org/10.3945/ajen.114.095539.

37. Ogino S, Liao X, Chan AT. Aspirin, PIK3CA mutation, and colorectal-cancer survival. N Engl J Med. 2013;368(3):289-90. https://doi.org/10.1056/NEJMc1214189.

38. Jayasekara H, MacInnis RJ, Williamson EJ, Hodge AM, Clendenning M, Rosty $\mathrm{C}$, et al. Lifetime alcohol intake is associated with an increased risk of KRAS+ and BRAF-/KRASbut not BRAF+ colorectal cancer. Int J Cancer. 2016;140(7):148593. https://doi.org/10.1002/ijc.30568.

39. Hughes LA, Williamson EJ, van Engeland M, Jenkins MA, Giles GG, Hopper JL, et al. Body size and risk for colorectal cancers showing BRAF mutations or microsatellite instability: a pooled analysis. Int J Epidemiol. 2012;41(4):1060-72. https://doi.org/10. 1093/ije/dys055. This study was the first to successfully pool MPE data when considering risk of molecular endpoints of CRC in relation to lifestyle factors, to improve precision estimates.

40. English DR, Young JP, Simpson JA, Jenkins MA, Southey MC, Walsh MD, et al. Ethnicity and risk for colorectal cancers showing somatic BRAF V600E mutation or $\mathrm{CpG}$ island methylator phenotype. Cancer Epidemiol Biomark Prev. 2008;17(7):1774-80. https://doi.org/10.1158/1055-9965.EPI-08-0091.

41. Luchtenborg M, Weijenberg MP, Kampman E, van Muijen GN, Roemen GM, Zeegers MP, et al. Cigarette smoking and colorectal cancer: APC mutations, hMLH1 expression, and GSTM1 and GSTT1 polymorphisms. Am J Epidemiol. 2005;161(9):806-15. https://doi.org/10.1093/aje/kwi114.

42. Weijenberg MP, Aardening PW, de Kok TM, de Goeij AF, van den Brandt PA. Cigarette smoking and KRAS oncogene mutations in sporadic colorectal cancer: results from the Netherlands cohort study. Mutat Res. 2008;652(1):54-64. https://doi.org/10.1016/j. mrgentox.2007.12.008.

43. Bongaerts BW, de Goeij AF, van den Brandt PA, Weijenberg MP. Alcohol and the risk of colon and rectal cancer with mutations in the K-ras gene. Alcohol. 2006;38(3):147-54. https://doi.org/10.1016/j. alcohol.2006.06.003.

44. Bongaerts BW, de Goeij AF, de Vogel S, van den Brandt PA, Goldbohm RA, Weijenberg MP. Alcohol consumption and distinct molecular pathways to colorectal cancer. Br J Nutr. 2007;97(3): 430-4. https://doi.org/10.1017/S0007114507381336.

45. Hughes LA, Simons CC, van den Brandt PA, Goldbohm RA, de Goeij AF, de Bruine AP, et al. Body size, physical activity and risk of colorectal cancer with or without the $\mathrm{CpG}$ island methylator phenotype (CIMP). PLoS One. 2011;6(4):e18571. https://doi.org/ 10.1371/journal.pone.0018571.

46. Hughes LA, van den Brandt PA, de Bruine AP, Wouters KA, Hulsmans S, Spiertz A, et al. Early life exposure to famine and colorectal cancer risk: a role for epigenetic mechanisms. PLoS One. 2009;4(11):e7951. https://doi.org/10.1371/journal.pone. 0007951.

47. Hogervorst JG, de Bruijn-Geraets D, Schouten LJ, van Engeland M, de Kok TM, Goldbohm RA, et al. Dietary acrylamide intake and the risk of colorectal cancer with specific mutations in KRAS and APC. Carcinogenesis. 2014;35(5):1032-8. https://doi.org/10.1093/ carcin/bgu002.

48. Brink M, Weijenberg MP, De Goeij AF, Schouten LJ, Koedijk FD, Roemen GM, et al. Fat and K-ras mutations in sporadic colorectal cancer in The Netherlands cohort study. Carcinogenesis. 2004;25(9):1619-28. https://doi.org/10.1093/carcin/bgh177.

49. Weijenberg MP, Luchtenborg M, de Goeij AF, Brink M, van Muijen GN, de Bruine AP, et al. Dietary fat and risk of colon and rectal cancer with aberrant MLH1 expression, APC or KRAS genes. Cancer Causes Control. 2007;18(8):865-79. https://doi. org/10.1007/s10552-007-9032-6.

50. de Vogel S, van Engeland M, Luchtenborg M, de Bruine AP, Roemen GM, Lentjes MH, et al. Dietary folate and APC mutations in sporadic colorectal cancer. J Nutr. 2006;136(12):3015-21.

51. Gilsing AM, Fransen F, de Kok TM, Goldbohm AR, Schouten LJ, de Bruine AP, et al. Dietary heme iron and the risk of colorectal cancer with specific mutations in KRAS and APC. Carcinogenesis. 2013;34(12):2757-66. https://doi.org/10.1093/carcin/bgt290. This 
article presents data from one of the first MPE studies used to test hypotheses with regards to mutagenic effects and CRC.

52. de Vogel S, Bongaerts BW, Wouters KA, Kester AD, Schouten LJ, de Goeij AF, et al. Associations of dietary methyl donor intake with MLH1 promoter hypermethylation and related molecular phenotypes in sporadic colorectal cancer. Carcinogenesis. 2008;29(9): 1765-73. https://doi.org/10.1093/carcin/bgn074.

53. de Vogel S, Wouters KA, Gottschalk RW, van Schooten FJ, de Goeij AF, de Bruine AP, et al. Dietary methyl donors, methyl metabolizing enzymes, and epigenetic regulators: diet-gene interactions and promoter $\mathrm{CpG}$ island hypermethylation in colorectal cancer. Cancer Causes Control. 2011;22(1):1-12. https://doi.org/10. 1007/s10552-010-9659-6.

54. Simons CC, van den Brandt PA, Stehouwer CD, van Engeland M, Weijenberg MP. Body size, physical activity, early-life energy restriction, and associations with methylated insulin-like growth factor-binding protein genes in colorectal cancer. Cancer Epidemiol Biomark Prev. 2014;23(9):1852-62. https://doi.org/10. 1158/1055-9965.EPI-13-1285.

55. van Engeland M, Weijenberg MP, Roemen GM, Brink M, de Bruine AP, Goldbohm RA, et al. Effects of dietary folate and alcohol intake on promoter methylation in sporadic colorectal cancer: the Netherlands cohort study on diet and cancer. Cancer Res. 2003;63(12):3133-7.

56. Schernhammer ES, Giovannucci E, Baba Y, Fuchs CS, Ogino S. B vitamins, methionine and alcohol intake and risk of colon cancer in relation to $\mathrm{BRAF}$ mutation and $\mathrm{CpG}$ island methylator phenotype (CIMP). PLoS One. 2011;6(6):e21102. https://doi.org/10.1371/ journal.pone.0021102.

57. Schernhammer ES, Giovannucci E, Kawasaki T, Rosner B, Fuchs CS, Ogino S. Dietary folate, alcohol and B vitamins in relation to LINE-1 hypomethylation in colon cancer. Gut. 2010;59(6):794-9. https://doi.org/10.1136/gut.2009.183707.

58. Limsui D, Vierkant RA, Tillmans LS, Wang AH, Weisenberger DJ, Laird PW, et al. Cigarette smoking and colorectal cancer risk by molecularly defined subtypes. J Natl Cancer Inst. 2010;102(14): 1012-22. https://doi.org/10.1093/jnci/djq201.

59. Hoffmeister M, Blaker H, Kloor M, Roth W, Toth C, Herpel E, et al. Body mass index and microsatellite instability in colorectal cancer: a population-based study. Cancer Epidemiol Biomark Prev. 2013;22(12):2303-11. https://doi.org/10.1158/1055-9965.EPI-130239.

60. Curtin K, Samowitz WS, Wolff RK, Herrick J, Caan BJ, Slattery ML. Somatic alterations, metabolizing genes and smoking in rectal cancer. Int J Cancer. 2009;125(1):158-64. https://doi.org/10.1002/ ijc. 24338 .

61. Samowitz WS, Albertsen H, Sweeney C, Herrick J, Caan BJ, Anderson KE, et al. Association of smoking, CpG island methylator phenotype, and V600E BRAF mutations in colon cancer. J Natl Cancer Inst. 2006;98(23):1731-8. https://doi.org/10.1093/jnci/ djj468.

62. Slattery ML, Curtin K, Anderson K, Ma KN, Ballard L, Edwards S, et al. Associations between cigarette smoking, lifestyle factors, and microsatellite instability in colon tumors. J Natl Cancer Inst. 2000;92(22):1831-6. https://doi.org/10.1093/jnci/92.22.1831.

63. Slattery ML, Anderson K, Curtin K, Ma KN, Schaffer D, Samowitz W. Dietary intake and microsatellite instability in colon tumors. Int J Cancer. 2001;93(4):601-7. https://doi.org/10.1002/ijc.1370.
64. Slattery ML, Curtin K, Sweeney C, Levin TR, Potter J, Wolff RK, et al. Diet and lifestyle factor associations with $\mathrm{CpG}$ island methylator phenotype and BRAF mutations in colon cancer. Int J Cancer. 2007;120(3):656-63. https://doi.org/10.1002/ijc.22342.

65. Poynter JN, Haile RW, Siegmund KD, Campbell PT, Figueiredo JC, Limburg P, et al. Associations between smoking, alcohol consumption, and colorectal cancer, overall and by tumor microsatellite instability status. Cancer Epidemiol Biomark Prev. 2009;18(10): 2745-50. https://doi.org/10.1158/1055-9965.EPI-09-0517.

66. Diergaarde B, van Geloof WL, van Muijen GN, Kok FJ, Kampman E. Diet and truncating APC mutations in sporadic colon tumours. IARC Sci Publ. 2002;156:505-6.

67. Diergaarde B, Braam H, van Muijen GN, Ligtenberg MJ, Kok FJ, Kampman E. Dietary factors and microsatellite instability in sporadic colon carcinomas. Cancer Epidemiol Biomark Prev. 2003; 12(11 Pt 1):1130-6.

68. Diergaarde B, van Geloof WL, van Muijen GN, Kok FJ, Kampman E. Dietary factors and the occurrence of truncating APC mutations in sporadic colon carcinomas: a Dutch population-based study. Carcinogenesis. 2003;24(2):283-90. https://doi.org/10.1093/ carcin/24.2.283.

69. Bautista D, Obrador A, Moreno V, Cabeza E, Canet R, Benito E, et al. Ki-ras mutation modifies the protective effect of dietary monounsaturated fat and calcium on sporadic colorectal cancer. Cancer Epidemiol Biomark Prev. 1997;6(1):57-61.

70. Martinez F, Fernandez-Martos C, Quintana MJ, Castells A, Llombart A, Iniguez F, et al. APC and KRAS mutations in distal colorectal polyps are related to smoking habits in men: results of a cross-sectional study. Clin Transl Oncol. 2011;13(9):664-71. https://doi.org/10.1007/s12094-011-0712-z.

71. Dahlin AM, Palmqvist R, Henriksson ML, Jacobsson M, Eklof V, Rutegard J, et al. The role of the $\mathrm{CpG}$ island methylator phenotype in colorectal cancer prognosis depends on microsatellite instability screening status. Clin Cancer Res. 2010;16(6):1845-55. https://doi. org/10.1158/1078-0432.CCR-09-2594.

72. Diergaarde B, Vrieling A, van Kraats AA, van Muijen GN, Kok FJ, Kampman E. Cigarette smoking and genetic alterations in sporadic colon carcinomas. Carcinogenesis. 2003;24(3):565-71. https://doi. org/10.1093/carcin/24.3.565.

73. Botteri E, Iodice S, Bagnardi V, Raimondi S, Lowenfels AB, Maisonneuve P. Smoking and colorectal cancer: a meta-analysis. JAMA. 2008;300(23):2765-78. https://doi.org/10.1001/jama. 2008.839.

74. De Sousa EMF, Wang X, Jansen M, Fessler E, Trinh A, de Rooij LP, et al. Poor-prognosis colon cancer is defined by a molecularly distinct subtype and develops from serrated precursor lesions. Nat Med. 2013;19(5):614-8. https://doi.org/10.1038/nm.3174.

75. Hughes LA, Khalid-de Bakker CA, Smits KM, van den Brandt PA, Jonkers $\mathrm{D}$, Ahuja $\mathrm{N}$, et al. The $\mathrm{CpG}$ island methylator phenotype in colorectal cancer: progress and problems. Biochim Biophys Acta. 2012;1825(1):77-85. https://doi.org/10.1016/j.bbcan.2011.10.005.

76. Hughes LA, Melotte V, de Schrijver J, de Maat M, Smit VT, Bovee $\mathrm{JV}$, et al. The $\mathrm{CpG}$ island methylator phenotype: what's in a name? Cancer Res. 2013;73(19):5858-68. https://doi.org/10.1158/00085472.CAN-12-4306. 